Check for updates

Cite this: Chem. Sci., 2019, 10, 3353

๑ All publication charges for this article have been paid for by the Royal Society of Chemistry

Received 18th January 2019

Accepted 3rd February 2019

DOI: $10.1039 / c 9 s c 00302 a$

rsc.li/chemical-science

\section{Reductive annulations of arylidene malonates with unsaturated electrophiles using photoredox/Lewis acid cooperative catalysis $\dagger$}

\author{
Rick C. Betori, Benjamin R. McDonald and Karl A. Scheidt (D)*
}

A cooperative Lewis acid/photocatalytic reduction of salicylaldehyde-derived arylidene malonates provides access to a versatile, stabilized radical anion enolate. Using these unusual umpolung operators, we have developed a novel route to access densely functionalized carbo- and heterocycles through a radical annulation addition pathway.
The development of annulation strategies has proved invaluable in organic synthesis, particularly for the construction of complex natural products. ${ }^{1}$ In a broad sense, annulation reactions can be divided into two electron and one electron approaches, where two electron annulation tactics include the venerable Diels-Alder, Michael and Dieckmann reactions, as well as general nucleophilic additions and alkylations. Conversely, one-electron annulation methods have focused on using halogenated starting materials and tin reagents, where seminal reports by Curran and Stork were revolutionary for the advent of radical annulations. ${ }^{2}$ Despite these elegant approaches, the use of stoichiometric tin hydrides is problematic both due to toxicity and purification problems, driving the need for the development of radical annulation reactivity accessed through catalytic methods using nonprefunctionalized starting materials. ${ }^{3}$ The development of photoredox chemistry has rendered the catalytic generation of open shell intermediates relatively facile due to the natural abundance and ease of use of visible light, as well as the superior chemoselectivity observed compared with traditional methodologies for radical-based approaches. ${ }^{4}$

Along these lines, the use of photoredox chemistry to access inverse polarity concepts, termed umpolung, have emerged as instrumental. ${ }^{5}$ Specifically, the generation of ketyl radical species (e.g. $\mathrm{d}_{1}$ umpolung operators) through the reduction of carbonyl derivatives has been a major focus. ${ }^{6}$ Since carbonyls are typically characterized by strongly negative redox potentials $\left(E_{1 / 2} \text { red }=-1.93 \mathrm{~V} v s \text {. SCE for benzaldehydes }\right)^{7}$ the development of cooperative catalytic systems to effect said reduction

Department of Chemistry, Center for Molecular Innovation and Drug Discovery, Northwestern University, 2145 Sheridan Road, Evanston, Illinois 60208, USA. E-mail: Scheidt@northwestern.edu

$\dagger$ Electronic supplementary information (ESI) available. CCDC 1835356. For ESI and crystallographic data in CIF or other electronic format see DOI: $10.1039 / \mathrm{c} 9 \mathrm{sc} 00302 \mathrm{a}$ potential have been highly explored to afford annulations, reductive couplings and radical-radical couplings (Fig. 1). ${ }^{\mathbf{s}}$

Similarly, $d_{3}$ umpolung operators in photoredox have been explored. ${ }^{9}$ Yoon et al. pioneered a cooperative catalytic approach to enone $\beta$-umpolung reactivity using a photoredox/Lewis acid approach to afford [2+2], and [3+2] cycloadditions. ${ }^{10}$ Following Yoon's seminal work on enone $\beta$-umpolung reactivity, recent reports have focused on using bifunctional and cooperative catalytic approaches in photoredox catalysis to access new chemical reactivity. ${ }^{11}$ However, new directions and opportunities remain unexplored in this area, primarily due to the

\section{General Two-Electron Strategies For Annulations}

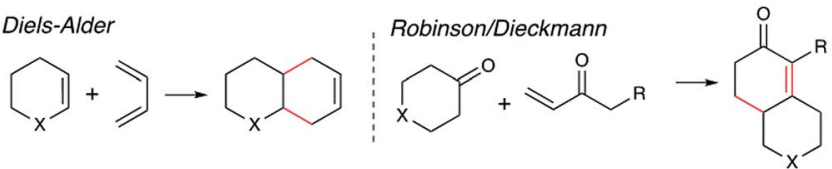

C-C Reductive Annulations Through Stabilized Radical Enolate

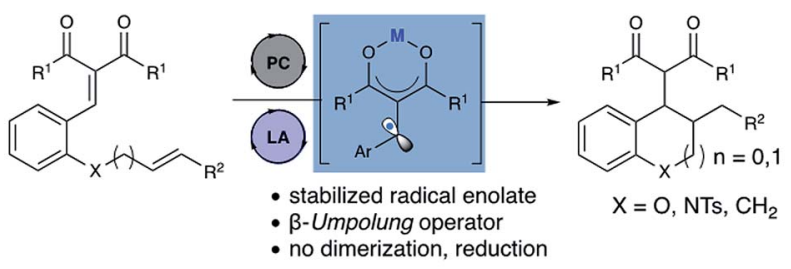

Common Heterocycles Accessible by Annulations in Bioactive Small Molecules

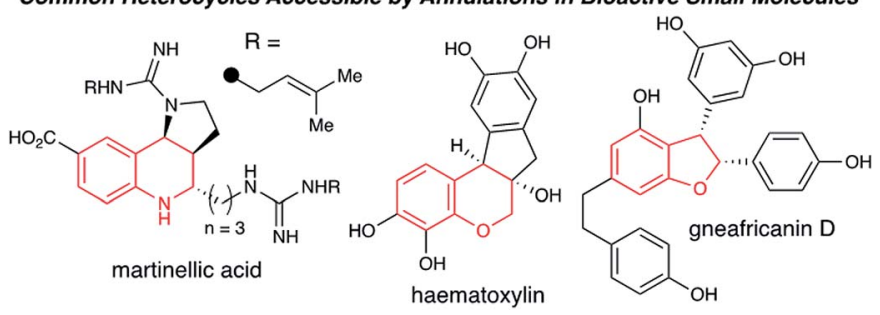

Fig. 1 Selected annulation strategies. 
inherent limitations of bifunctional catalytic manifolds, which restrict reactivity and generalizability as well.

As part of our program to generate new opportunities in $\beta$ umpolung chemistry, we recently reported the use of arylidene malonates as substrates in photoredox/Lewis acid cooperative catalysis to afford radical-radical cross coupling, radical dimerizations, and transfer hydrogenations. ${ }^{12}$ As a major goal of this study, we focused on designing a stabilized $\beta$-umpolung operator intermediate, with the hypothesis that a more stabile radical anion would enable underexplored chemical reactivity, namely intermolecular radical couplings, rather than the dimerization reactions often seen with enone-derived radical anions (e.g. cinnamates, $E_{1 / 2}$ red $=-2.3 \mathrm{~V} v s$. SCE). ${ }^{13}$ In this regard, we demonstrated that arylidene malonates $\left(E_{1 / 2}\right.$ red $=$ $-1.57 \mathrm{~V}$ for phenyl arylidene malonate $v s$. SCE),${ }^{14}$ demonstrated a drastic shift in reduction potential upon complexation with a Lewis acid $\left(E_{1 / 2}\right.$ red $=-0.37 \mathrm{~V}$ for phenyl arylidene malonate $v s$. SCE). By utilizing arylidene malonates, this cooperative catalytic approach afforded a stabilized $\beta$-radical enolate intermediate exhibiting reactivity divergent from reductive species generated from conventional enones, presumably due to greater persistence of the resonance-stabilized radical anion. Herein we report a cooperative Lewis acid/photoredox reductive enolate annulation strategy to provide densely functionalized carbo and heterocycles.

Chroman and related heterocycles are a diverse class of bioactive small molecules that our lab have previously prepared and investigated for their wide range of biological activities in anti-cancer models. ${ }^{15}$ We envisioned that the arylidene malonate-derived $\beta$-umpolung operator could grant access to previously unprepared derivatives. We initiated our studies with 1a, which was readily accessible in 2 steps from salicylaldehyde, using a variety of photocatalysts and blue LEDs, the results of which are summarized in Table 1 . Gratifyingly, we found that the desired chromane product was formed with scandium triflate in acetonitrile using photocatalyst dF-Ir and Hantzsch ester $(\mathrm{HEH})$ in $81 \%$ yield with a $1.2: 1 \mathrm{dr}$. A variety of other bidentate Lewis acids were investigated, all of which were capable of affording the title reaction, albeit with decreased yield in comparison to scandium triflate (entries 1-4). A survey of transition metal photocatalysts identified dF-Ir as optimal. Interestingly, organocatalysts of the dicyanobenzene family performed as well as dF-Ir, with diphenyl aniline organocatalyst DPAIPN $^{16}$ providing the desired product in comparable $85 \%$ yield and diastereoselectivity. Solvent evaluation confirmed acetonitrile to be the optimal solvent, whereas aprotic and protic (see ESI $\dagger$ ) were shown to be less successful. Evaluations of alternative stoichiometric hydrogen atom donors (DIPEA, $\mathrm{NEt}_{3}, \mathrm{NBu}_{3}, \mathrm{BT}$ ) were capable of delivering 2a in slightly decreased yields relative to the $\mathrm{HEH}$; where a slight increase in diastereoselectivity was observed ( $2: 1 \mathrm{dr}$ observed with $\mathrm{NEt}_{3}$ ) at a precipitous loss of yield (entries 9-12). The rationale for this observed increase in diastereoselectivity could be due to coordination from the radical cation of $\mathrm{NEt}_{3}$ with the malonate, providing a facial selectivity to facilitate increased diastereoselectivity, or that the $\mathrm{C}-\mathrm{C}$ bond formation is reversible and that the diastereoselectivity is determined, at least in part, by
Table 1 Optimization of the reaction conditions

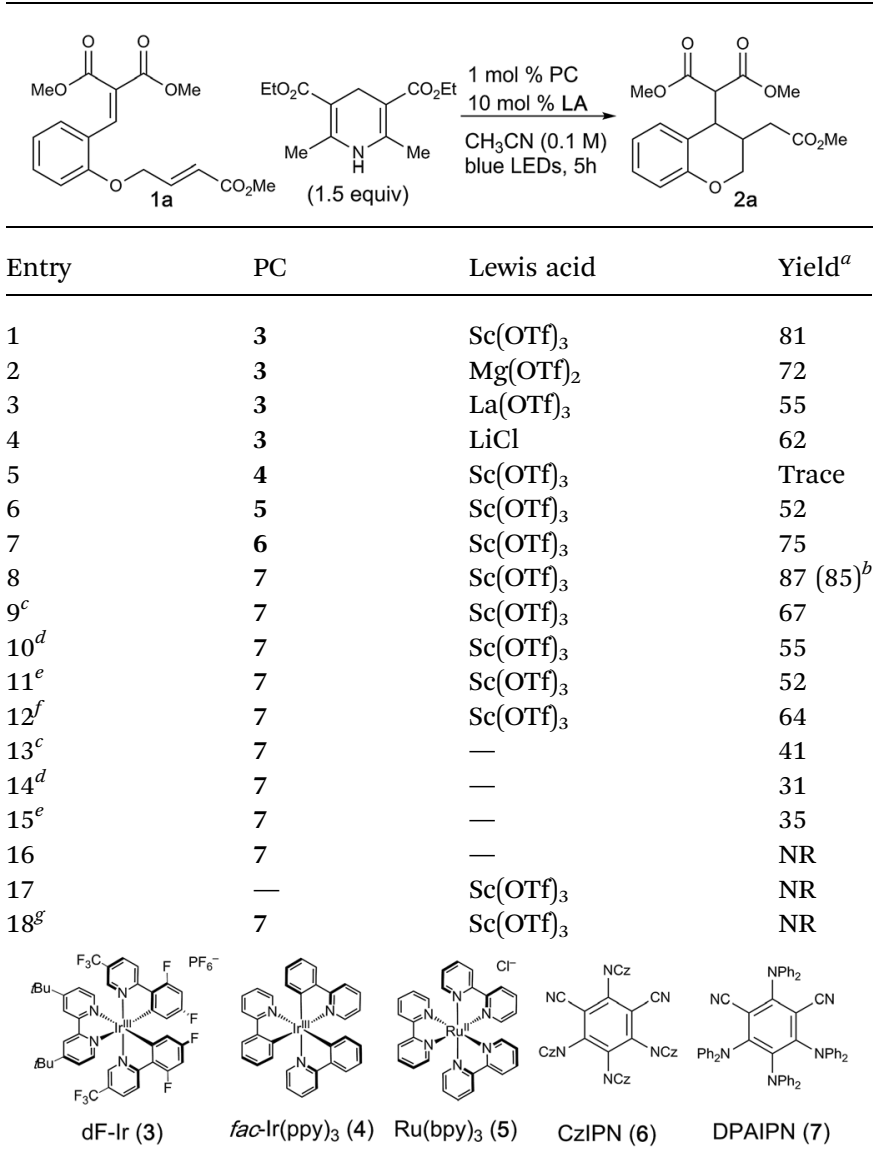

${ }^{a}$ Yield determined by GC with bibenzyl as internal standard. Product was observed in a $1.2: 1 \mathrm{dr}$ ratio. ${ }^{b}$ Yield of isolated product. ${ }^{c}$ DIPEA used instead of HEH. ${ }^{d} \mathrm{Net}_{3}$ used instead of $\mathrm{HEH} .{ }^{e} \mathrm{NBu}_{3}$ used instead of HEH. ${ }^{f}$ BT used instead of HEH. ${ }^{g}$ No light. DIPEA = diisopropylethylamine, $\mathrm{NEt}_{3}=$ triethylamine, $\mathrm{BT}=2$-phenyldihydrobenzothiazoline.

the relative rates of hydrogen atom transfer. As tertiary amines have been used previously for activation of carbonyls for reduction, we evaluated DIPEA, $\mathrm{NEt}_{3}$ and $\mathrm{NBu}_{3}$ in the absence of $\mathrm{Sc}(\mathrm{OTf})_{3}$, where drastically lower yields were observed (entries 13-15). In this instance, it is believed that upon initial single electron reduction, the oxidized nitrogen atom in DIPEA, $\mathrm{NEt}_{3}$ or $\mathrm{NBu}_{3}$ can form a 2 -center/3-e $\mathrm{e}^{-}$interaction, ${ }^{17}$ or after a $[1,2]-\mathrm{H}$ shift, can serve a hydrogen-bond donor, ${ }^{18}$ which results in the oxidized amine serving as both the terminal reductant and the Lewis acid necessary for activation of $1 \mathbf{1 a}^{\mathbf{8 d , e}}$ A series of control experiments demonstrated that the reaction did not take place in the absence of light, photocatalyst or Lewis acid (entries 1618).

With these optimized conditions, we investigated a variety of substrates (Table 2). Generally, the desired products were obtained in good to excellent yields. Substrates bearing either electron-rich and electron-poor substituents were well tolerated; however, substrates with substitution at the 6-position did not provide the desired product, presumably due to reduced overlap 
Table 2 Reactions of salicylaldehyde derived arylidene malonates ${ }^{a}$

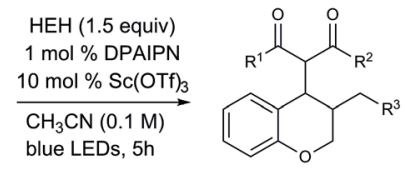

2

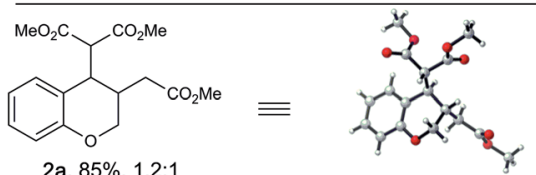

2a, $85 \%, 1.2: 1$<smiles>CC(=O)CC1COc2c(Cl)cccc2C1c1cccc(Cl)c1[18O]OC(C)=O</smiles>

$X$-ray of trans $2 a$

$\mathrm{MeO}_{2} \mathrm{C} Y \mathrm{CO}_{2} \mathrm{Me}$<smiles>CC(=O)CC1COc2ccccc2C1C(C)C</smiles>

$\mathrm{Br} \quad 2 \mathrm{c}, 70 \%, 1.2: 1$<smiles>CC(=O)CC1COc2c(O)cccc2C1C(C(C)=O)C(C)=O</smiles>

2d, $62 \%, 1.2: 1$

2e, $74 \%, 1.5: 1$<smiles>CC(=O)CC1COc2c(F)cccc2C1C(C(C)=O)C(C)=O</smiles><smiles>CC(=O)CC1COc2cc(F)ccc2C1C(C(C)C)C(C)C</smiles>

<smiles>CC(=O)CC1COc2cc(C)ccc2C1C(OC(C)=O)C(C)=O</smiles>

2f, $68 \%, 1.2: 1$

$$
2 \mathrm{~g}, 84 \%, 1.2: 1
$$

$\mathrm{MeO}_{2} \mathrm{C} Y \mathrm{CO}_{2} \mathrm{Me}$<smiles>CCC(C)C(C(C)C)C1c2cc(F)ccc2OCC1CC(C)=O</smiles>

\section{$2 \mathrm{~h}, 88 \%, 1.2: 1$}<smiles>CC(=O)OCC1COc2c(Br)cc(Br)cc2C1C(C(C)=O)C(C)=O</smiles>

$2 \mathrm{k}, 91 \%, 1.1: 1$<smiles>CC(=O)C1C(C(C)=O)C2C(=O)Oc3ccc4ccccc4c3C2C1C(C)=O</smiles><smiles>CCOC(=O)C(C(=O)OCC)C1c2ccccc2OCC1COC</smiles><smiles>CC(=O)OCC1COc2ccc(C)cc2C1C(C(C)=O)C(C)=O</smiles>

2i, $91 \%, 1.2: 1$ $\mathrm{MeO}_{2} \mathrm{C} \smile \mathrm{CO}_{2} \mathrm{Me}$<smiles>CCC1c2cc(Cl)cc(C)c2OCC1CCOC</smiles>

2l, $90 \%, 1.2: 1$<smiles>CCCC(=O)OC(C(=O)OCC)C1c2ccccc2OCC1C(=O)OC</smiles>

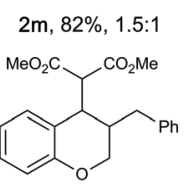

$$
\text { 2n, } 86 \%, 1.2: 1
$$$$
\mathrm{MeO}_{2} \mathrm{C} Y \mathrm{CO}_{2} \mathrm{Me}
$$<smiles>N#CCC1COc2ccccc2C1</smiles><smiles>CCOCC1COc2ccc3c(c2)C1C(C(=O)O[Na])C(=O)O3</smiles><smiles>O=C(O)CC1COc2ccccc2C1C(C(=O)O)C(=O)O</smiles>

2q, $81 \%, 1.2: 1$<smiles>CCCCCCCC=CC=C(C(C)=O)C1CCc2ccccc21</smiles><smiles>CCOC=C1COc2ccccc2C1C(C(=O)OCC)C(C)C</smiles>

$2 \mathrm{~s}, 88 \%, 1.2: 1$

2t, $71 \%, 1: 1$ Z:E

2u, $81 \%, 1: 1$ Z:E

${ }^{a}$ Reaction conditions: $1(0.2 \mathrm{mmol})$, HEH $(0.3 \mathrm{mmol})$, PC 7 (1 mol\%), $\mathrm{Sc}(\mathrm{OTf})_{3}(10 \mathrm{~mol} \%)$, degassed $\mathrm{CH}_{3} \mathrm{CN}(2.0 \mathrm{~mL})$ was irradiated with a blue LED $(456 \mathrm{~nm})$ for $5 \mathrm{~h}$. Reported yields are determined after isolation by column chromatography.

between the enone and aryl $\pi$-systems. Diversity could be introduced into the dicarbonyl moiety to tolerate a variety of diesters (2n, 2o) in good to excellent yields, albeit as a complex mixture of diastereomers. The unsaturated electrophile could be varied to facilitate access to benzyl (2p) and nitrile (2q) substituted chromanes in excellent yields. Replacement of the

olefin electrophile with alkyne electrophiles proceeded with excellent yields $(\mathbf{2 t}, \mathbf{2} \mathbf{u})$, albeit as a mixture of $Z / E$ isomers.

Furthermore, we were pleased to find that modification of the starting material to access tetrahydroquinolines (2v) and tetrahydronaphthalenes (2w) were also successful in high yields, illustrating the capability of this methodology to access a wide range of carbo and heterocyclic scaffolds in high efficiency. Attempts to access dihydrobenzofuran was successful, albeit with slightly diminished yields ( $2 x, 72 \%$ yield), where the remaining mass balance is the saturated arylidene malonate species. This is presumably due to the decreased electrophilicity of the vinylogous carbonate starting material due to hyperconjugation (Table 3). ${ }^{19}$

Unfortunately, substrates designed to allow access to quaternary centers (either derived from 2'-hydroxyacetophenone or from senecioic acid) were not successful in this reaction, presumably due to decreased reactivity of the resulting $\beta$-radical enolate intermediate and decreasing electrophilicity of the tethered alkene respectively. The importance of the dicarbonyl moiety was validated as a means for Lewis acid coordination, as substrates derived from Meldrum's acid showed no conversion under the optimized conditions. An intermolecular reductive coupling between 8 and methyl acrylate was unsuccessful, where only transfer hydrogenation to afford 9 was observed. This likely indicates that reduction of the resulting radical anion proceeds more rapidly than radical conjugate addition (Fig. 2).

Notably, we were able to demonstrate this reaction on multigram scale, where 2a was accessed in similar yields under identical reaction conditions, further highlighting the potential of this reaction. Additionally, the DPAIPN photocatalyst was recovered after column chromatography in $80 \%$ yield. The recovered DPAIPN was subsequently used in a multi-gram scale reaction without loss of yield, giving this methodology additional utility due to the ability to recover and reuse the catalyst (Fig. 3).

A practical advantage of this strategy is the ease of synthetically elaborating these products. A one-pot Krapcho/

Table 3 Reactions of arylidene malonates affording different core scaffolds $^{a}$

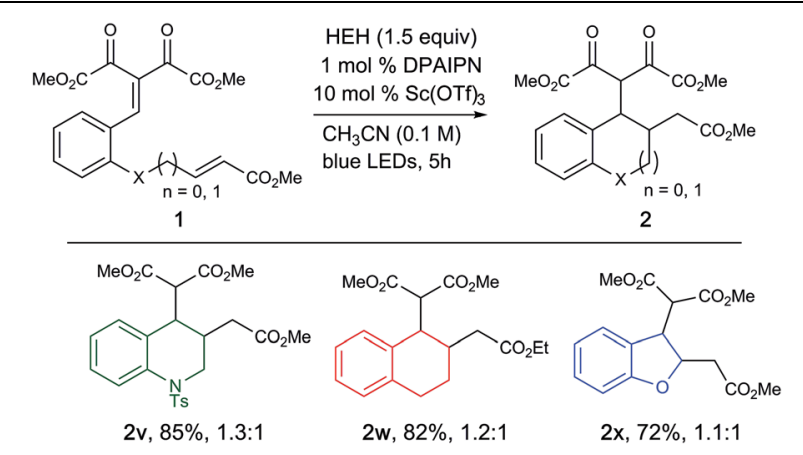

${ }^{a}$ Reaction conditions: 1 (0.2 mmol), HEH $(0.3 \mathrm{mmol})$, PC 7 (1 mol\%), $\mathrm{Sc}(\mathrm{OTf})_{3}(10 \mathrm{~mol} \%)$, degassed $\mathrm{CH}_{3} \mathrm{CN}(2.0 \mathrm{~mL})$ was irradiated with a blue LED (456 nm) for $5 \mathrm{~h}$. Reported yields are determined after isolation by column chromatography. 
A) Substrates Unsuccessful in the Reductive Annulation Reaction
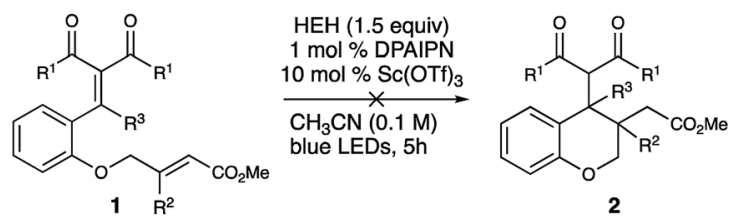

(c)
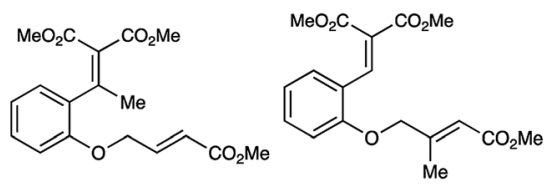

minimal conversion

no conversion

B) Intermolecular Reductive Coupling Reaction
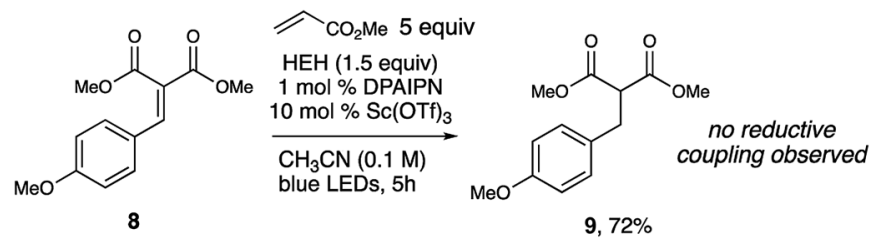

Fig. 2 Reductive annulation reaction extension.

Dieckmann/Krapcho sequence with cis-2a proceeded in $85 \%$ yield, affording an interesting [6,6,5] fused ring system (Fig. 4).

To probe the mechanism of this process, we investigated whether this photoredox process can propagate through a chain process rather than the presumed closed-catalytic photoredox cycle. ${ }^{20}$ We were pleased to find that upon using a "light/dark" experiment ${ }^{21}$ that product formation was only observed during periods of irradiation (Fig. 5). While supporting our mechanistic hypothesis, "light/dark" experiments are typically not sufficient to fully elucidate whether a process proceeds through a closed-catalytic cycle as opposed to a propagating chain process. $^{22}$

As a follow up to these studies, we demonstrated that this reaction has a quantum yield of 1.0 , indicating that the reaction does not propagate through a radical chain process (see $\mathrm{ESI} \dagger$ for details).

To further study the mechanism of the $\beta$-radical enolate formation, we employed fluorescence quenching techniques with 1a as a model substrate. A Stern-Volmer analysis revealed that 1a does not quench the excited state of DPAIPN $\left(E_{1 / 2}\right.$ red $=$ $-1.52 \mathrm{~V} v s$. SCE) in acetonitrile at $25{ }^{\circ} \mathrm{C}$ (Fig. 6). However, inclusion of $100 \mathrm{~mol} \% \mathrm{Sc}(\mathrm{OTf})_{3}$ resulted in a large decrease in the measured fluorescence. Notably, control experiments demonstrated that $\mathrm{Sc}(\mathrm{OTf})_{3}$ itself does not quench the DPAIPN

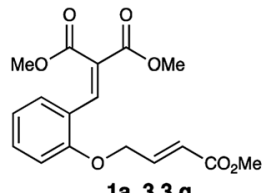

1a, $3.3 \mathrm{~g}$

with recovered cat, $2.6 \mathrm{~g}$

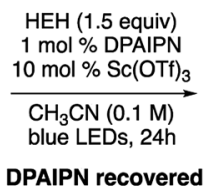

in $80 \%$ yield

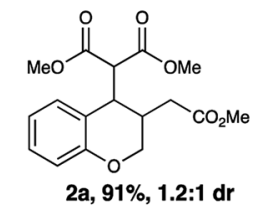

with recovered cat, $88 \%$ yield
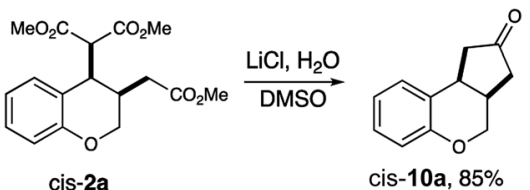

Fig. 4 Krapcho/Dieckmann synthesis of fused ring system.

excited state, indicating that pre-complexation of Sc(OTf $)_{3}$ with $1 \mathbf{a}$ is necessary for generation of the radical anion. Furthermore, variation of the stoichiometry of $\mathrm{Sc}(\mathrm{OTf})_{3}$ and $1 \mathrm{a}$ revealed that the quenching process exhibits a first-order dependence on each component (see ESI $\dagger$ ). Notably, these results only provide evidence that a $\mathrm{Sc}(\mathrm{OTf})_{3} / \mathbf{1 a}$ complex is necessary for arylidene malonate activation and is not indicative of oxidative quenching of DPAIPN by $\mathrm{Sc}(\mathrm{OTf})_{3} / \mathbf{1 a}$. To evaluate the possibility of a reductive quenching mechanism, we conducted Stern-Volmer analysis with the $\mathrm{HEH}$, where quenching of DPAIPN fluorescence by the $\mathrm{HEH}$ is observed. Both 1a and a 1a/100 mol\% $\mathrm{Sc}(\mathrm{OTf})_{3}$ complex were also added to the $\mathrm{HEH}$ for Stern-Volmer analysis, where minimal changes to the fluorescence quenching profile were observed. This trend was evident across 10, 25 and $50 \mathrm{~mol} \% \mathrm{Sc}(\mathrm{OTf})_{3}$ as well. This is likely indicative that the $\mathrm{HEH}$ is responsible for quenching the photo-excited DPAIPN, not the $\mathrm{Sc}(\mathrm{OTf})_{3} / \mathbf{1 a}$ complex. Fluorescence quenching experiments with $\mathrm{NBu}_{3}$ was also evaluated, where the inclusion of $\mathbf{1 a}$ and a $\mathbf{1 a}$ / $100 \mathrm{~mol} \% \mathrm{Sc}(\mathrm{OTf})_{3}$ complex resulted in no change to the quenching profile of DPAIPN by $\mathrm{NBu}_{3}$ (see ESI $\dagger$ ).

While both processes are thermodynamically comparable, it is unlikely that an oxidative quenching mechanism predominates, primarily because of the decreased possibility of finding a $\mathrm{Sc}(\mathrm{OTf})_{3} / \mathbf{1 a}$ complex due to catalytic $\mathrm{Sc}(\mathrm{OTf})_{3}$ relative to superstoichiometric $\mathrm{HEH}$. We investigated the transformation of 1a to 2a using stoichiometric $\operatorname{Sc}(\mathrm{OTf})_{3}$ and found no significant difference in the reactivity profile or yield between using 10 and $100 \mathrm{~mol} \% \mathrm{Sc}(\mathrm{OTf})_{3}$. We found that using stoichiometric $\mathrm{NBu}_{3}$ was able to provide $2 \mathrm{a}$ without the presence of $\mathrm{Sc}(\mathrm{OTf})_{3}$ in $35 \%$ yield, indicating that reductive quenching of the photocatalyst is likely the initial step of this mechanism, where
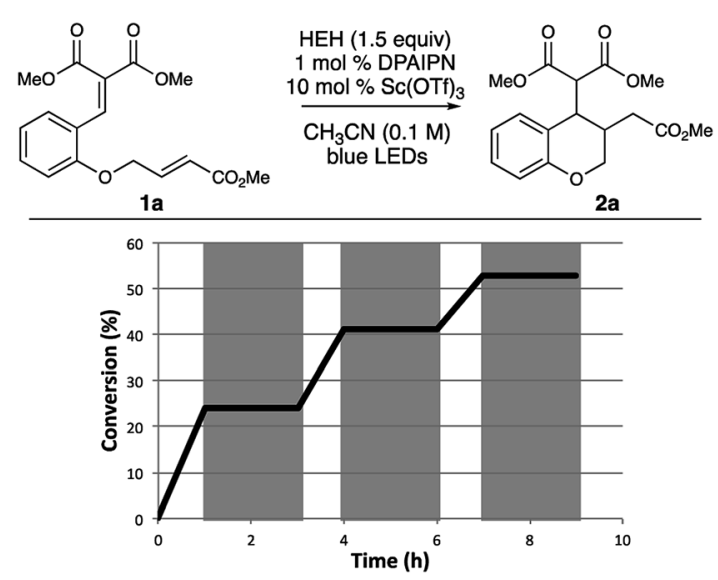

Fig. 5 Light/dark experiments.

Fig. 3 Gram-scale reaction. 


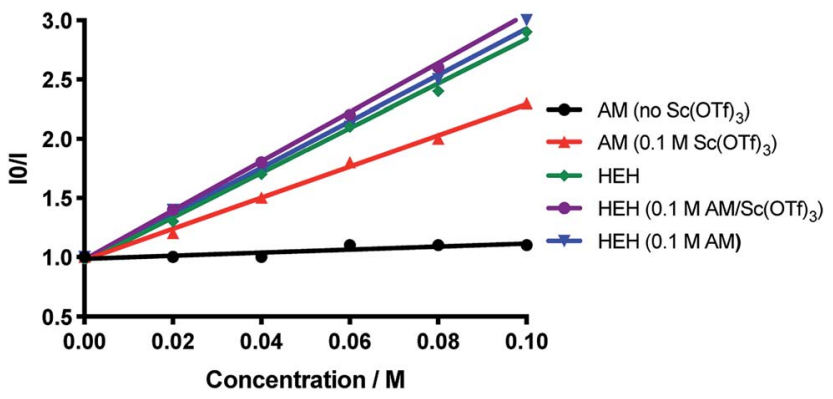

Fig. 6 Stern-Volmer fluorescence quenching analysis.

oxidative quenching is thermodynamically unfavourable (Table 1, entry 15). Moreover, as with transition metal photocatalysts, reductive quenching of DPAIPN is kinetically favourable relative to oxidative quenching, leading us to believe that a reductive quenching pathway is the primary pathway. ${ }^{23}$ Furthermore, $\operatorname{Ir}(\mathrm{ppy})_{3}$, which would only be viable in an oxidative quenching cycle, only yielded trace product (Table 1, entry 5).

To further understand the nature of the $\mathrm{Sc}(\mathrm{OTf})_{3} / \mathbf{1}$ a complex, UV-Vis spectroscopic characterization was carried out. Interestingly, the $\mathrm{Sc}(\mathrm{OTf})_{3} / \mathbf{1 a}$ complex demonstrated a considerable difference in the UV-Vis spectrum relative to 1a alone, where there is an additional shoulder peak around $380-410 \mathrm{~nm}$. While this demonstrates that the $\mathrm{Sc}(\mathrm{OTf})_{3} / \mathbf{1}$ a complex can absorb blue LED light, no reactivity is observed without the DPAIPN photocatalyst present, indicating that it is unlikely that the $\mathrm{Sc}(\mathrm{OTf})_{3} / \mathbf{1 a}$ complex can generate any intermediates that result in consumption of $\mathbf{1 a}$. To confirm that the $\mathrm{Sc}(\mathrm{OTf})_{3} / \mathbf{1 a}$ complex does not undergo productive photoredox reaction pathways in the absence of DPAIPN, we irradiated 1a with $10 \mathrm{~mol} \% \mathrm{Sc}(\mathrm{OTf})_{3}$ and superstoichiometric DIPEA, $\mathrm{NEt}_{3}, \mathrm{NBu}_{3}$ and HEH. No

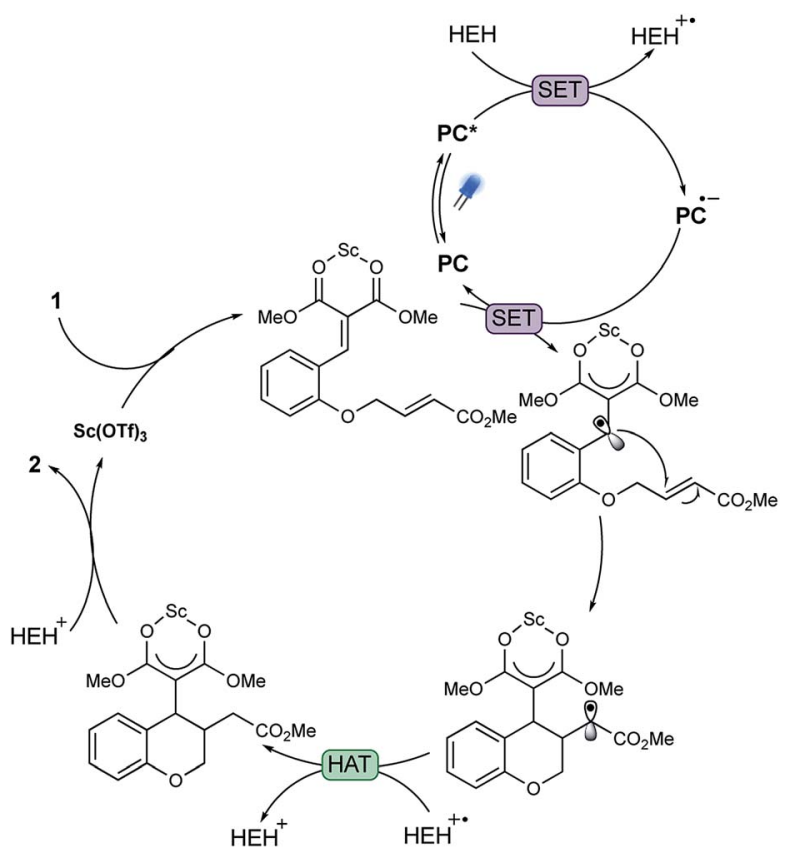

Fig. 7 Proposed pathway. conversion of 1a was observed in any case. Finally, the UV-Vis profile of 1a showed no change in the presence of either DIPEA, $\mathrm{NEt}_{3}$ or $\mathrm{NBu}_{3}(100 \mathrm{~mol} \%)$, indicating that the amines themselves are not interacting with 1a, but instead need to undergo a single electron reduction to complex with 1a (see ESI $\dagger$ for details).

With this data in hand and in line with our previous work on photoredox/Lewis acid cooperative catalysis, we propose the following mechanism for the observed reactivity (Fig. 7): irradiation with visible light results in the formation of excited DPAIPN photocatalyst, a capable oxidant $\left(E_{1 / 2}\right.$ ox $=1.10 \mathrm{~V} v s$. SCE). Reduction of the resulting DPAIPN excited state by HEH $\left(E_{1 / 2}\right.$ ox $=0.89 \mathrm{~V} v$ s. SCE) furnishes a strongly reducing DPAIPN catalyst $\left(E_{1 / 2}\right.$ red $=-1.52 \mathrm{~V} v$ s. SCE). Subsequently, the reduced DPAIPN species transfers an electron to the Lewis acid-arylidene malonate complex, producing the nucleophilic radical anion and regenerating the ground state DPAIPN catalyst. The radical anion is able to add into the unsaturated bond, forming the chromane ring and a stabilized radical, which upon hydrogen atom transfer from the corresponding HEH radical cation, leads to the enolate complex. Subsequent proton transfer from the protonated HEH leads to the desired product.

\section{Conclusions}

A Lewis acid/photoredox cooperative catalytic manifold is capable of generating stabilized radical anion species from salicylaldehyde-derived arylidene malonates has been developed. This reactive intermediate undergoes intramolecular conjugate addition with pendent unsaturated electrophiles to afford structurally diverse chromanes. This platform sets the stage for further development of $\beta$-umpolung reactivity via photoredox catalysis, which is currently underway in our laboratory.

\section{Conflicts of interest}

The authors declare no competing financial interests.

\section{Acknowledgements}

We thank the National Institute of General Medical Sciences (R01GM073072, F31GM116532 to B. R. M. and T32GM105538 to R. C. B.) for financial support. R. C. B. was supported in part by the Chicago Cancer Baseball Charities at the Lurie Cancer Center of Northwestern University.

\section{Notes and references}

1 M. E. Jung, Tetrahedron, 1976, 32, 3.

2 (a) D. P. Curran and P. A. van Elburg, Tetrahedron Lett., 1989, 30, 2501; (b) D. P. Curran and C. M. Seong, Tetrahedron, 1992, 48, 2175; (c) G. Stork, R. Mook, S. A. Biller and S. D. Rychnovsky, J. Am. Chem. Soc., 1983, 105, 3741; (d) G. Stork, H. S. Suh and G. Kim, J. Am. Chem. Soc., 1991, 113, 7054. 
3 (a) A. Studer and D. P. Curran, Nat. Chem., 2014, 6, 765; (b) A. Studer and D. P. Curran, Angew. Chem., Int. Ed., 2016, $55,58$.

4 (a) C. K. Prier, D. A. Rankic and D. W. C. MacMillan, Chem. Rev., 2013, 113, 5322; (b) M. H. Shaw, J. Twilton and D. W. C. MacMillan, J. Org. Chem., 2016, 81, 6898.

5 (a) F. R. Petronijević, M. Nappi and D. W. C. MacMillan, J. Am. Chem. Soc., 2013, 135, 18323; (b) J. A. Terrett, M. D. Clift and D. W. C. MacMillan, J. Am. Chem. Soc., 2014, 136, 6858; (c) J. L. Jeffrey, F. R. Petronijević and D. W. C. MacMillan, J. Am. Chem. Soc., 2015, 137, 8404; (d) E. Fava, A. Millet, M. Nakajima, S. Loescher and M. Rueping, Angew. Chem., Int. Ed., 2016, 55, 6776; (e) A. L. Fuentes de Arriba, F. Urbitsch and D. J. Dixon, Chem. Commun., 2016, 52, 14434; (f) R. Wang, M. Ma, X. Gong, G. B. Panetti, X. Fan and P. J. Walsh, Org. Lett., 2018, 20, 2433; (g) W. Xu, J. Ma, X.-A. Yuan, J. Dai, J. Xie and C. Zhu, Angew. Chem., Int. Ed., 2018, 57, 10357.

6 (a) L. Qi and Y. Chen, Angew. Chem., Int. Ed., 2016, 55, 13312; (b) K. N. Lee, Z. Lei and M.-Y. Ngai, J. Am. Chem. Soc., 2017, 139, 5003; (c) H.-H. Zhang and S. Yu, J. Org. Chem., 2017, 82, 9995; (d) M. Chen, X. Zhao, C. Yang and W. Xia, Org. Lett., 2017, 19, 3807; (e) J. A. Leitch, A. L. Fuentes de Arriba, J. Tan, O. Hoff, C. M. Martínez and D. Dixon, J. Chem. Sci., 2018, 9, 6653.

7 O. Ishitani, S. Yanagida, S. Takamuku and C. Pac, J. Org. Chem., 1987, 52, 2790.

8 (a) K. T. Tarantino, P. Liu and R. R. Knowles, J. Am. Chem. Soc., 2013, 135, 10022; (b) M. N. Hopkinson, B. Sahoo, J. L. Li and F. Glorius, Chem.-Eur. J., 2014, 20, 3874; (c) H. G. Yayla and R. R. Knowles, Synlett, 2014, 25, 2819; (d) M. Nakajima, E. Fava, S. Loescher, Z. Jiang and M. Rueping, Angew. Chem., Int. Ed., 2015, 54, 8828; (e) E. Fava, M. Nakajima, A. L. P. Nguyen and M. Rueping, J. Org. Chem., 2016, 81, 6959; $(f)$ E. C. Gentry and R. R. Knowles, Acc. Chem. Res., 2016, 49, 1546; $(g)$ D. C. Miller, K. T. Tarantino and R. R. Knowles, Top. Curr. Chem., 2016, 374, 30; (h) K. L. Skubi, T. R. Blum and T. P. Yoon, Chem. Rev., 2016, 116, 10035; (i) T. P. Yoon, Acc. Chem. Res., 2016, 49, 2307.

9 (a) M. Neumann and K. Zeitler, Chem.-Eur. J., 2013, 19, 6950; (b) G. Pandey, S. Hajra, M. K. Ghorai and K. R. Kumar, J. Am. Chem. Soc., 1997, 119, 8777; (c) M. T. Crimmins, Chem. Rev., 1988, 88, 1453; (d) D. I. Schuster, G. Lem and N. A. Kaprinidis, Chem. Rev., 1993, 93, 3; (e) J. Streuff and A. Gansäuer, Angew. Chem., Int. Ed., 2015, 54, 14232; $(f)$ M.-H. Larraufie, R. Pellet, L. Fensterbank, J.-P. Goddard, E. Lacôte, M. Malacria and C. Ollivier, Angew. Chem., Int. Ed., 2011, 50, 4463.

10 (a) M. A. Ischay, M. E. Anzovino, J. Du and T. P. Yoon, J. Am. Chem. Soc., 2008, 130, 12886; (b) M. A. Ischay, Z. Lu and T. P. Yoon, J. Am. Chem. Soc., 2010, 132, 8572; (c) J. Du, L. R. Espelt, I. A. Guzei and T. P. Yoon, Chem. Sci., 2011, 2, 2115; (d) A. E. Hurtley, M. A. Cismesia, M. A. Ischay and T. P. Yoon, Tetrahedron, 2011, 67, 4442; (e) Z. Lu, M. Shen and T. P. Yoon, J. Am. Chem. Soc., 2011, 133, 1162; $(f)$ T. P. Yoon, ACS Catal., 2013, 3, 895; $(g)$ J. Du and
T. P. Yoon, J. Am. Chem. Soc., 2009, 131, 14604; (h) E. L. Tyson, E. P. Farney and T. P. Yoon, Org. Lett., 2012, 14, 1110.

11 (a) J. J. Murphy, D. Bastida, S. Paria, M. Fagnoni and P. Melchiorre, Nature, 2016, 532, 218; (b) L. Dell'Amico, V. M. Fernández-Alvarez, F. Maseras and P. Melchiorre, Angew. Chem., Int. Ed., 2017, 56, 3304; (c) M. Silvi, C. Verrier, Y. P. Rey, L. Buzzetti and P. Melchiorre, Nat. Chem., 2017, 9, 868; (d) D. Mazzarella, G. E. M. Crisenza and P. Melchiorre, J. Am. Chem. Soc., 2018, 140, 8439; (e) C. Verrier, N. Alandini, C. Pezzetta, M. Moliterno, L. Buzzetti, H. B. Hepburn, A. Vega-Peñaloza, M. Silvi and P. Melchiorre, ACS Catal., 2018, 8, 1062; $(f)$ F. F. de Assis, X. Huang, M. Akiyama, R. A. Pilli and E. Meggers, J. Org. Chem., 2018, 83, 10922-10932; (g) S.-X. Lin, G.-J. Sun and Q. Kang, Chem. Commun., 2017, 53, 7665; (h) P. Bonilla, Y. P. Rey, C. M. Holden and P. Melchiorre, Angew. Chem., Int. Ed., 2018, 57, 12819; (i) G. Goti, B. Bieszczad, A. VegaPeñaloza and P. Melchiorre, Angew. Chem., Int. Ed., 2019, 58, 1213-1217.

12 B. R. McDonald and K. A. Scheidt, Org. Lett., 2018, 20, 6877. 13 (a) T. Shono, I. Nishiguchi and H. Ohmizu, J. Am. Chem. Soc., 1977, 99, 7396; (b) G. Zhao, C. Yang, L. Guo, H. Sun, R. Lin and W. Xia, J. Org. Chem., 2012, 77, 6302.

14 D. Gang, Y. Jun, Y. Xiao-ping and X. Hui-jun, Tetrahedron, 1990, 46, 5967.

15 (a) R. L. Farmer and K. A. Scheidt, Chem. Sci., 2013, 4, 3304; (b) R. L. Farmer, M. M. Biddle, A. E. Nibbs, X. Huang, R. C. Bergan and K. A. Scheidt, ACS Med. Chem. Lett., 2010, 1, 400; (c) M. M. Biddle, M. Lin and K. A. Scheidt, J. Am. Chem. Soc., 2007, 129, 3830; (d) A. E. Nibbs, A.-L. Baize, R. M. Herter and K. A. Scheidt, Org. Lett., 2009, 11, 4010; (e) B. R. McDonald, A. E. Nibbs and K. A. Scheidt, Org. Lett., 2015, 17, 98; (f) L. Xu, R. Gordon, R. Farmer, A. Pattanayak, A. Binkowski, X. Huang, M. Avram, S. Krishna, E. Voll, J. Pavese, J. Chavez, J. Bruce, A. Mazar, A. Nibbs, W. Anderson, L. Li, B. Jovanovic, S. Pruell, M. Valsecchi, G. Francia, R. Betori, K. Scheidt and R. Bergan, Nat. Commun., 2018, 9, 2454; $(g)$ A. E. Nibbs and K. A. Scheidt, Eur. J. Org. Chem., 2012, 2012, 449.

16 (a) J. Luo and J. Zhang, ACS Catal., 2016, 6, 873; (b) N. A. Romero and D. A. Nicewicz, Chem. Rev., 2016, 116, 10075.

17 S. Humbel, I. Côte, N. Hoffmann and J. Bouquant, J. Am. Chem. Soc., 1999, 121, 5507.

18 D. Akalay, G. Dürner, J. W. Bats, M. Bolte and M. W. Göbel, J. Org. Chem., 2007, 72, 5618.

19 N. J. Foy, K. C. Forbes, A. M. Crooke, M. D. Gruber and J. S. Cannon, Org. Lett., 2018, 20, 5727-5731.

20 M. A. Cismesia and T. P. Yoon, Chem. Sci., 2015, 6, 5426.

21 (a) Y. Miyake, K. Nakajima and Y. Nishibayashi, J. Am. Chem. Soc., 2012, 134, 3338; (b) C.-J. Wallentin, J. D. Nguyen, P. Finkbeiner and C. R. J. Stephenson, J. Am. Chem. Soc., 2012, 134, 8875; (c) B. Sahoo, M. N. Hopkinson and F. Glorius, J. Am. Chem. Soc., 2013, 135, 5505; (d) S. Mizuta, K. M. Engle, S. Verhoog, O. Galicia-López, M. O'Duill, M. Médebielle, K. Wheelhouse, G. Rassias, A. L. Thompson 
and V. Gouverneur, Org. Lett., 2013, 15, 1250; (e) S. H. Oh, Y. R. Malpani, N. Ha, Y.-S. Jung and S. B. Han, Org. Lett., 2014, 16, 1310.

22 (a) G. M. Burnett and H. W. Melville, Chem. Rev., 1954, 54, 225; (b) R. G. McIntosh, R. L. Eager and J. W. T. Spinks,
Science, 1960, 131, 992; (c) R. G. McIntosh, R. L. Eager and J. W. T. Spinks, Can. J. Chem., 1965, 43, 3490.

23 (a) S. P. Pitre, C. D. McTiernan and J. C. Scaiano, Acc. Chem. Res., 2016, 49, 1320; (b) D. M. Arias-Rotondo and J. K. McCusker, Chem. Soc. Rev., 2016, 45, 5803. 